\title{
COMMUNICATIONS
}

\section{Pyrolysis/Methylation of Soil Fulvic Acids: Benzenecarboxyllc Acids Revisited}

\author{
C. Salz-Jimenez \\ Instituto de Recursos Naturales y Agrobiologia, C.S.I.C., Apartado 1052, 41080 Sevilla, Spain
}

\section{Introduction}

Fulvic acid (FA) is, perhaps, the most complex fraction of soil humic substances due to its extremely variable composition depending on the nature of the environment (1) and the isolation method (2). Practically all available techniques and methods have been applied to FAs (3), in order to understand their chemical structure, but in spite of extensive studies, their nature is still a matter of debate.

Chemical degradations have been widely used to characterize FAs in terms of structural units. However, they provide only partial information on the molecular constituents. For instance, acid hydrolysis reveals the presence of sugars and some phenols, while oxidations yield alkanes, fatty acids, phenolic acids, and benzenecarboxylic acids (4). Benzenecarboxylic acids were considered the building blocks of the humic molecule in the 1970s, and on the basis of permanganate oxidations and other analyses, Schnitzer and Khan (4) proposed a model made up of phenolic and benzenecarboxylic acids held together by hydrogen bonds, which were suggested to account for a significant part of the FA structure.

Recently, a debate emerged on the chemical structure of humic substances. In fact, on the basis of pyrolysis data, it was proposed that the skeleton of humic acid (HA) is based on alkylbenzenes, -naphthalenes, and -phenanthrenes (5). This structure was subsequently criticized (6). Whether this model could be extended to FA is unknown, and therefore it is important to develop new methods for investigating the structure of humic substances in general and FA in particular.

Pyrolysis gas chromatography/mass spectrometry has been used for the last 10 years as the main microanalytical method for investigating intractable macromolecular materials ( 7 ). The technique has been demonstrated to provide useful information on bio- and geopolymers. However, the yield from pyrolysis products is low due to condensation on the pyrolysis chamber walls and column limitations. In some artificial polymers the pyrolysis products can be representative of the whole molecule, but in complex materials such as humic substances, this representativity is doubtful and biased by technical restrictions.

One of the most striking features of humic substances is the virtual absence of carboxyl-containing compounds other than fatty acids in the pyrolysate. The fatty acids and many other lipids are considered as evaporation products rather than pyrolysis products, as they are free and can be solvent-extractable ( 8 ). Fatty acids inside a pyrolysis unit evaporate readily, and to a lesser extent, thermal decarboxylation occurs. However, fatty acids cannot account for the high carboxyl carbon resonances found in ${ }^{13} \mathrm{C}$ NMR of FAs (9), and other carboxylcontaining structures, absent from conventional pyrolysis analyses, have to form part of the molecule.

Simultaneous pyrolysis/methylation procedures have been applied to synthetic polymers and plant esters for the last 10 years $(10,11)$. Basically, the method consists of the derivatization of samples containing carboxyl and/ or hydroxyl groups with an alkylating reagent. Tetramethylammonium salts of organic acids can be converted to methyl ester and the corresponding byproduct in the pyrolysis unit, thus the functional groups are directly protected. In this paper, two FAs previously studied by conventional pyrolysis (12) are investigated following pyrolytic methylation. This novel method reveals that FA pyrolysates contain a variety of compounds with carboxyls and phenolic hydroxyls, which are condensed onto the pyrolysis chamber walls, or thermally degraded in conventional pyrolysis, and therefore absent in previous analyses. Identification of these compounds provides useful data on the structure of FAs.

\section{Materials and Methods}

Soil Fulvic Acids. The FAs were extracted from the A horizon of Santa Olalla soil, a Typic Xerochrept in the north of the Huelva province, Spain, and from the $B_{h}$ horizon of Armadale soil, a Haplaquord in Prince Edward Island, Canada. The latter was kindly supplied by Dr. M. Schnitzer. Details of the soils and their FA fractions have been reported elsewhere $(4,13)$. Both FAs were investigated using conventional pyrolysis, and their chemical nature was discussed in light of their pyrolysis products in a previous report (12).

Pyrolysis/Methylation. The FA $(500 \mu \mathrm{g})$ was deposited in a Curie-point small hollow ferromagnetic cylinder (temperature $500^{\circ} \mathrm{C}$ ) and wetted with $5 \mu \mathrm{L}$ of a $25 \% \mathrm{w} / \mathrm{w}$ aqueous solution of tetramethylammonium hydroxide (10). The cylinder was slightly dried with a $\mathrm{N}_{2}$ flow and immediately inserted in the pyrolyzer. The analysis was performed in a Fisons gas chromatograph/mass spectrometer Model GC $8000 / \mathrm{MD} 800$ coupled to a Fischer 0316 Curie-point pyrolyzer, using a $30 \mathrm{~m} \times 0.25 \mathrm{~mm}$ SPB-5 column (film thickness $0.25 \mu \mathrm{m}$ ). The GC oven was held at $25^{\circ} \mathrm{C}$ by a cryogenic unit and programed to $280^{\circ} \mathrm{C}$, at a rate of $5^{\circ} \mathrm{C} / \mathrm{min}$. The final temperature was held for $20 \mathrm{~min}$.

It has been suggested that the use of a small hollow ferromagnetic cylinder could originate secondary pyrolysis 


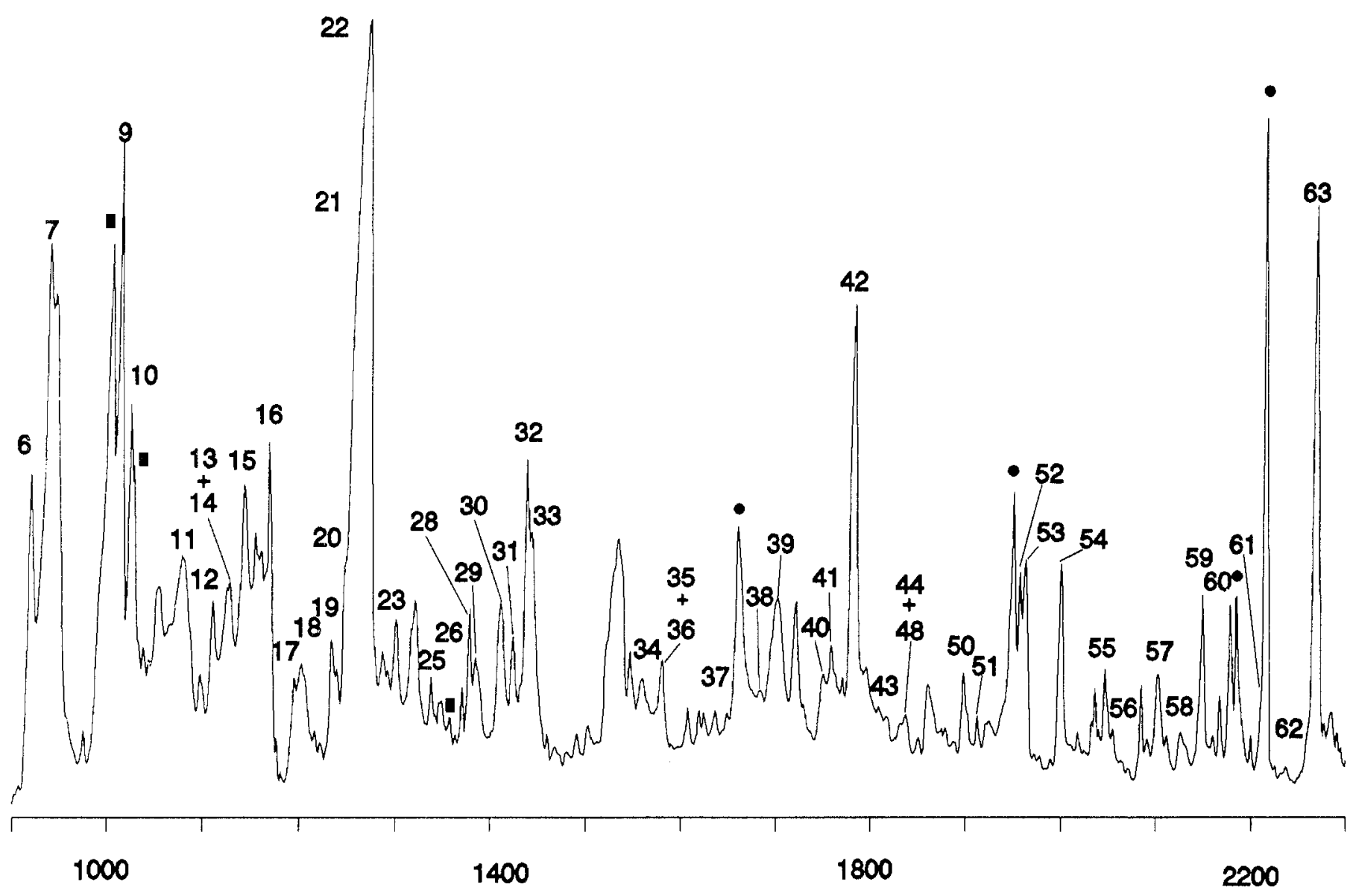

\section{Scan numbers}

Figure 1. Partial total ion current chromatogram of Santa Olalla fulvic acid. Peak numbers refer to Tables 2 and 3 . Signs are indicative of ( $\square$ ) pyrrolidine derivatives and $(O) C_{12}, C_{14}, C_{16: 1}$, and $C_{16}$ fatty acids, respectively.

\begin{tabular}{|c|c|c|}
\hline class of compds ${ }^{a}$ & S. Olalla range ${ }^{b}$ & Armadale range \\
\hline $\begin{array}{l}n \text {-alkanes } \\
n \text {-alkenes } \\
n \text {-fatty acids } \\
\alpha, \omega \text {-dicarboxylic acids }{ }^{c} \\
\text { alkylbenzenes } \\
\text { alkylnaphthalenes } \\
\text { alkylindenes } \\
\text { alkylfluorenes } \\
\text { alkylbenzofurans } \\
\text { alkylfurancarboxylic acids } \\
\text { alkylphenols } \\
\text { alkylguaiacols } \\
\text { aikyl-2,6-dimethoxyphenols } \\
\text { phenolic acids } \\
\text { benzenecarboxylic acids } b, c\end{array}$ & $\begin{array}{l}\mathrm{C}_{9}-\mathrm{C}_{33} \\
\mathrm{C}_{12}-\mathrm{C}_{30} \\
\mathrm{C}_{4}-\mathrm{C}_{30} \\
\mathrm{C}_{6}-\mathrm{C}_{26} \\
\mathrm{C}_{0}-\mathrm{C}_{24} \\
\mathrm{C}_{0}-\mathrm{C}_{4} \\
\mathrm{C}_{0}-\mathrm{C}_{2} \\
\mathrm{C}_{0}-\mathrm{C}_{2} \\
\mathrm{C}_{0}-\mathrm{C}_{2} \\
\mathrm{C}_{0}-\mathrm{C}_{1} \\
\mathrm{C}_{0}-\mathrm{C}_{4} \\
\mathrm{C}_{0}-\mathrm{C}_{3} \\
\mathrm{C}_{0} \\
\mathrm{C}_{1}-\mathrm{C}_{3} \\
\mathrm{C}_{1}-\mathrm{C}_{3}\end{array}$ & $\begin{array}{l}\mathrm{C}_{9}-\mathrm{C}_{27} \\
\mathrm{C}_{9}-\mathrm{C}_{27} \\
\mathrm{C}_{8}-\mathrm{C}_{26} \\
\mathrm{C}_{4}, \mathrm{C}_{8}-\mathrm{C}_{10} \\
\mathrm{C}_{0}-\mathrm{C}_{21} \\
\mathrm{C}_{0}-\mathrm{C}_{5} \\
\mathrm{C}_{0}-\mathrm{C}_{1} \\
\mathrm{C}_{0}-\mathrm{C}_{1} \\
\mathrm{C}_{0}-\mathrm{C}_{2} \\
\mathrm{C}_{0}-\mathrm{C}_{2} \\
\mathrm{C}_{0}-\mathrm{C}_{3} \\
\mathrm{C}_{0}-\mathrm{C}_{2} \\
\mathrm{C}_{1} \\
\mathrm{C}_{1}-\mathrm{C}_{3}\end{array}$ \\
\hline
\end{tabular}

a $\alpha, \omega$-Dicarboxylic, furancarboxylic, phenolic, and benzenecarboxylic acids were absent in conventional pyrolysis. ${ }^{b}$ Range denotes number of carbon atoms in alkyl chains, except for benzenecarboxylic acids, which refer to the number of carboxyl groups. ${ }^{c}$ As methyl esters. ${ }^{d}$ Also fully methylated compounds.

products through multiple collisions between the fragments and the hot cylinder walls (14). However, it has been demonstrated that the use of both wires and cylinders produces the same pyrolysis products in model phenolic acids. Therefore, for the purpose of better distribution and contact of powdered samples with the tetramethylammonium hydroxide solution, the cylinder was preferred.
The pyrolysis products were identified by comparison of their mass spectra with a self-collected data bank of plant and soil polymers and humic fractions $(2,7,8,12$, 15). In some cases, identification was achieved by a computer, with an NBS library of about 54000 spectra. However, in this case the computer matching was carefully checked with standards, when possible, and taken into account together with the mass spectrometrist's experience.

\section{Results and Discussion}

Pyrolysis at $500^{\circ} \mathrm{C}$ was selected as previous experimental work with humic samples at temperatures ranging from 358 to $770^{\circ} \mathrm{C}$ revealed that $500^{\circ} \mathrm{C}$ was a good compromise for macromolecules containing polysaccharides, proteins, lignins, etc. (8).

The pyrolysate of the Santa Olalla FA (Figure 1) is a complex mixture from which 230 compounds have been identified. All carboxyl-containing compounds were found as methyl esters, which proved the methylation of these functional groups; therefore, these compounds are referred to as acids rather than esters. Table 1 summarizes the major series of compounds, noting the series of $\alpha, \omega$ dicarboxylic acids, as they were not previously found in conventional pyrolysis (12). Furancarboxylic acids (pyrolysis products from sugars and polysaccharides) and benzenecarboxylic acids with up to three carboxyl groups were identified, neither of which were observed in con- 


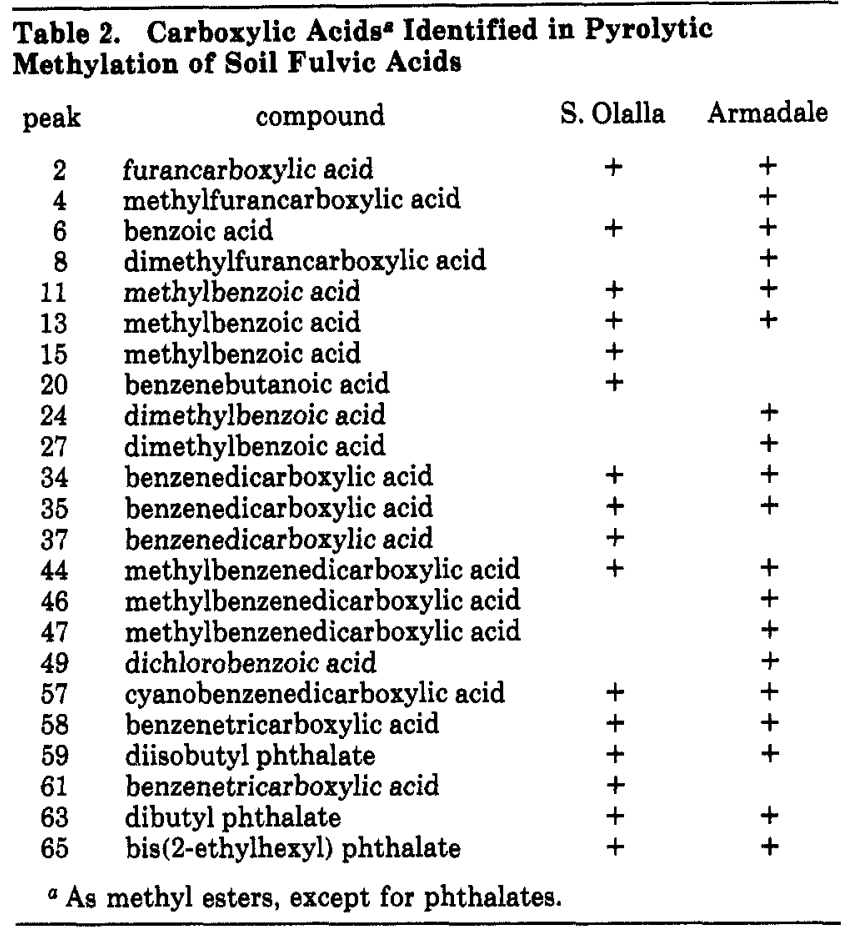

ventional pyrolysis. On the other hand, the series of aliphatic hydrocarbons, fatty acids, alkylbenzenes, and alkylnaphthalenes presented an extended range, only limited by the analytical conditions of the column and the temperature program. The even distribution of fatty acids, with maxima at $\mathrm{C}_{16}$, indicated a predominantly microbial/ plant origin for these compounds, and the $>\mathrm{C}_{27}$ alkanes are probably derived from higher plant waxes (16). The identification of prist-1-ene and phytadiene (pyrolysis products of tocopherols and chlorophylls, respectively), previously found in a pyrolysate of $\mathrm{HA}$, also points to a plant origin for the bulk of the soil lipids (8).

A characteristic signature of this FA is the abundance of lignin-derived phenols, among which the p-coumaryl, guaiacyl, and syringyl series can be discerned. The identification of derivatives from the three lignin units agrees with the nature of the lignin synthesized by the autochthonous vegetation-a meadow of gramineous, Medicago and Trifolium (13). However, the high number of benzenecarboxylic acids (Table 2) and phenols (Table 3 ) in the pyrolysate must be noted. The phenols and phenolic acids are related to lignin units. Lignins are characterized by a large number of free $\mathrm{C}_{3}$ side chains and by a dominant $\beta-0-4$ linkage. This determines that free side chains are accessible to microbial degradation. The final degradation step of the side chain is the formation of a carboxyl group, although intermediate oxidation steps in the side chain have been observed (15). Carboxyl groups in $\mathrm{C}_{1} / \mathrm{C}_{3}$ side chains and phenols with fully and partially methylated hydroxyl groups (Table 3 ) are noticeable.

Other compounds identified in the Santa Olalla FA pyrolysate were pyrrolidine derivatives, amides, and dialkyl phthalates. Pyrrolidines are residues from Polyclar used to adsorb the FA fraction. Amides (namely $N, N$-dimethylamides) are thought to be byproducts from the derivatization method. Dialkyl phthalates could probably correspond to artifacts introduced during the extraction and purification procedures, as phthalates are known to be distributed in the environment and particularly in plastic packages of products used in laboratories.
Table 3. Phenols Identified in Pyrolytic Methylation of Soil Fulvic Acids

peak compound Oladk

Olalla Armadale

1 methoxybenzene

methoxymethylbenzene

phenol

guaiacol

1,2-dimethoxybenzene

1-ethenyl-4-methoxybenzene

hydroxybenzoic acid methyl ester ${ }^{a}$

methylguaiacol

cresol

methyl-1,2-dimethoxybenzene

dimethylphenol

dimethylphenol

trimethylphenol

dimethylguaiacol

ethylguaiacol

1,2,3-trimethoxybenzene

methoxybenzoic acid methyl ester

methoxybenzoic acid methyl ester

vinylguaiacol

diethylphenol

eugenol

methoxybenzoic acid methyl ester

2,6-dimethoxyphenol

trans-isoeugenol

methoxybenzenepropanoic

acid methyl ester

vanillic acid methyl ester

3,4-dimethoxyphenylethanone

dimethoxybenzoic acid methyl ester

3,4-dimethoxybenzoic acid methyl ester

43 hydroxybenzenedicarboxylic acid dimethyl ester ${ }^{a}$

45 hydroxybenzenedicarboxylic acid dimethyl ester ${ }^{a}$

48 3,4-dimethoxybenzeneacetic acid methyl ester

50 3-(4-methoxyphenyl)-2-propenoic acid methyl ester

51 3,4,5-trimethoxyphenylethanone

biphenol

53 3,4,5-trimethoxybenzoic acid methyl ester

54 methoxybenzenedicarboxylic acid dimethyl ester

55 3,4,5-trimethoxybenzyl methyl ether ${ }^{b}$

methoxydibenzofuran

60 3-(3,4-dimethoxyphenyl)-2-propenoic acid methyl ester

62 dimethoxybenzenedicarboxylic acid dimethyl ester

64 methoxybenzenetricarboxylic acid trimethyl ester

$\begin{array}{ll}+ & + \\ + & + \\ + & + \\ + & + \\ + & + \\ + & + \\ + & + \\ + & + \\ + & +\end{array}$

$+$

$+$

$+$

$+$

$+$

$+$

$+\quad+$

$+\quad+$

$+\quad+$

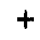

$+$

$+$

$+$

$+\quad+$

$+$

$+$

$+$

a The mass spectrum of this compound and the corresponding acetyloxy derivative are identical. ${ }^{b}$ Tentative identification.

The pyrolysate of Armadale FA is basically made up of the same pyrolysis products as those reported for the Santa Olalla FA (Tables 1-3). It is noteworthy that phenolic and benzenecarboxylic acids constitute a significant part of the aromatic pyrolysis products in Armadale FA. However, the most intriguing fact is the low number of lignin phenols identified in this FA (Table 3), and also in the HA (17), as compared to Santa Olalla FA. This could be explained by the fact that lignins have completed, to some extent, their microbial oxidation before accumulating in the $B_{h}$ horizon. On the other hand, the Santa Olalla FA, isolated from a surface horizon, contains lignin units in different decomposition stages, from which the basic 
$\mathrm{C}_{6}-\mathrm{C}_{3}$ unit can be traced (compounds 38, 50, and 60). Previous pyrolysis data confirm this, as demonstrated in a spruce lignin degraded by Coriolus versicolor (15), which yields guaiacyl units with different oxidation stages in the $\mathrm{C}_{3}$ side chain.

Of particular interest is the presence of benzenecarboxylic acids in FAs. In a previous paper, benzenecarboxylic acids were noted in the pyrolytic methylation of an aquatic FA, isolated by XAD-8 resin adsorption (18). The soil FAs reported herein were isolated by Polyclar (Santa Olalla) and by acid extraction (Armadale). Therefore, the benzenecarboxylic acids cannot be exclusively related to an extraction process, but must be independent of the isolation method, and may perhaps be characteristic components of FAs. Benzenecarboxylic acids have been identified in the Armadale FA by column fractionation, thin-layer, and gas chromatography (19). The identification of such compounds seems to validate both nondegradative and pyrolytic methylation methods.

Pyrolytic methylation of MWL lignins also revealed benzenecarboxylic acids among pyrolysis products, as well as the pyrolysate of a spruce MWL lignin degraded by basidiomycetes (unpublished data). It has been reported that the milling and isolation processes of lignins from woods result in the increase of hydroxyl groups (20). It could be speculated that isolation and/or microbial deg. radation also results in the recovery of benzenecarboxylic acids.

The presence of the series of alkylbenzenes and alkylnaphthalenes in both FA samples is to be noted. For Schulten et al. (5), the major thermal products resulting from the pyrolysis of two Canadian HAs (one of them the Armadale HA) were alkylbenzenes, -naphthalenes, and -phenanthrenes. They suggested that such compounds are significant structures in HAs and constitute its building blocks, released during low-temperature thermal degradation from an alkylaromatic structural network.

De Leeuw and Hatcher (6) seriously questioned these findings and concluded that the data of Schulten et al. (5) are highly biased and not at all representative of the HAs analyzed. Contrary to de Leeuw and Hatcher's opinion, it is believed that the data of Schulten et al. are representative of the HAs analyzed, as pyrolysis of the Armadale FA also revealed a similar series of compounds. However, the pyrolysis data are biased, not due to the malfunctioning of the pyrolysis equipment, as incorrectly suggested by de Leeuw and Hatcher (6), but because of the limitations imposed by conventional pyrolysis, as in all previous conventional pyrolysis papers dealing with polar macromolecular materials. These limitations, mainly the lack of functional groups in the many pyrolysis products obtained, have been demonstrated to be due to decarboxylation and dehydroxylation reactions in conventional pyrolysis, which obviously mask the results leading to confusion and seriously hampering any structural inference.

On the other hand, pyrolysis/methylation also has some minor limitations. The advantages and disadvantages of the method can be summarized as follows:

(1) Pyrolysis/methylation reveals the presence of carboxyl groups in aliphatic and aromatic structures, which are usually absent from conventional pyrolysis.
(2) Pyrolysis/methylation, however, does not completely protect carboxyl groups, since decarboxylation reactions are also produced. In fact, pyrolysis/methylation of model lignin phenols (e.g., vanillic acid) resulted in partial decarboxylation of the acid. Recoveries of 3,4-dimethoxybenzoic acid methyl ester accounted for $72.2 \%$ of the pyrolysis products, together with $24.0 \%$ of 1,2 -dimethoxybenzene, and $3.4 \%$ of 2-methoxyphenol. This demonstrated that the protection of carboxylic acids was not complete, and that some decarboxylation occurred in the original units. Also, phenolic hydroxyls were partially methylated even with an excess of methylation reagent.

To conclude, pyrolysis/methylation, an easy derivatization method, is proposed to be used alone or together with conventional pyrolysis for the analysis of complex macromolecular materials with carboxyl and hydroxyl groups. This technique is complementary to conventional pyrolysis and should be used to properly characterize humic substances and the functional groups.

\section{Literature Cited}

(1) Hatcher, P. G.; Spiker, E. C. In Humic Substances and their Role in the Environment; Frimmel, F. H., Christman, R. F., Eds.; Wiley: Oxford, 1988, pp 59-74.

(2) Saiz-Jimenez, C.; de Leeuw, J. W. J. Anal. Appl. Pyrol. 1986, 9, 99-119.

(3) Hayes, M. H. B.; MacCarthy, P.; Malcolm, R. L.; Swift, R. S. Eds. Humic Substances II. In Search of Structure Wiley-Interscience: Chichester, 1988.

(4) Schnitzer, M.; Khan, S. U. Humic Substances in the Environment; Marcel Dekker: New York, 1972.

(5) Schulten, H.-R.; Plage, B.; Schnitzer, M. Naturwissenschaften 1991, 78, 311-312.

(6) De Leeuw, J. W.; Hatcher, P. G. Naturwissenschaften 1992, $79,330-331$.

(7) Saiz-Jimenez, C. Origin and Chemical Nature of Soil Organic Matter; Delft University Press: Delft, 1988.

(8) Saiz-Jimenez, C.; de Leeuw, J. W. J. Anal. Appl. Pyrol. 1987, 11, 367-376.

(9) Hatcher, P. G.; Schnitzer, M.; Dennis, L. W.; Maciel, G. E. Soil Sci. Soc. Am. J. 1981, 45, 1089-1094.

(10) Challinor, J. M. J. Anal. Appl. Pyrol. 1991, 20, 1516-24.

(11) De Leeuw, J. W.; Baas, M. J. Anal. Appl. Pyrol. 1993, 26, 175-184.

(12) Saiz-Jimenez, C.; de Leeuw, J. W. Org. Geochem. 1984, 6 , 287-293.

(13) Saiz-Jimenez, C.; Hawkins, B. L.; Maciel, G. E. Org. Geochem. 1986, 6, 277-284.

(14) Meuzelaar, H. L. C.; Haverkamp, J.; Hileman, F.D.Pyrolysis Mass Spectrometry of Recent and Fossil Biomaterials. Compendium and Atlas; Elsevier: Amsterdam, 1982.

(15) Saiz-Jimenez, C.; de Leeuw, J. W. Org. Geochem. 1984, 6, $417-422$

(16) Simoneit, B. R. T. Int. J. Environ. Anal. Chem. 1986, 23, 207-237.

(17) Schulten, H.-R.; Schnitzer, M. Soil Sci. 1992, 153, 205-224.

(18) Saiz-Jimenez, C.; Hermosin, B.; Ortega-Calvo, J. J. Water Res. 1993, 27, 1693-1696.

(19) Ogner, G.; Schnitzer, M. Can. J. Chem. 1971, 49, 10531063.

(20) Pew, J. C. TAPPI 1957, 40, 553-558.

Received for review June 8, 1993. Revised manuscript received September 8, 1993. Accepted October 4, 1993. 